City University of New York (CUNY)

CUNY Academic Works

\title{
Our Year of Remote Reference: COVID19's Impact on Reference Services and Librarians
}

Sarah B. Cohn

CUNY City College

Rebecca Hyams

CUNY Borough of Manhattan Community College

\section{How does access to this work benefit you? Let us know!}

More information about this work at: https://academicworks.cuny.edu/cc_pubs/847

Discover additional works at: https://academicworks.cuny.edu

This work is made publicly available by the City University of New York (CUNY).

Contact: AcademicWorks@cuny.edu 


\title{
Our Year of Remote Reference: COVID19's Impact on Reference Services and Librarians
}

\author{
Sarah Cohn ${ }^{a}$ (D) and Rebecca Hyams ${ }^{b}$

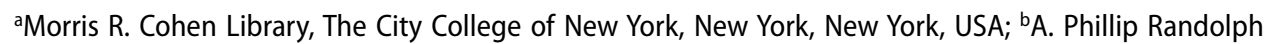 \\ Library, Borough of Manhattan Community College, New York, New York, USA
}

\begin{abstract}
After a full year of providing fully remote library reference due to the COVID-19 pandemic campus closures, this exploratory study looks at reference practices of libraries, and librarian response to those practices, at a large, urban, public university. This article focuses on the impact COVID-19 had on reference services themselves, as well as the perceptions of those who provide them.
\end{abstract}

\section{KEYWORDS}

Chat reference; academic libraries; Covid-19; reference services; remote reference

\section{Introduction}

As the COVID-19 case numbers in the United States began to climb in March of 2020, higher education institutions had to scramble to make the transition to remote teaching, learning, and other services. In New York City, which was hit exceptionally hard at the beginning of the pandemic's life in the United States, there was a real urgency in the air as we tried to mitigate the spread of a virus we knew little about at the time. Those of us in City University of New York (CUNY) system were, of course, no exception. CUNY colleges suspended virtually all in-person classes and services in March of 2020, which stretched on throughout the entire 2020-2021 academic year. The initial scramble of March 2020 eventually settled into something resembling a routine, with every library providing whatever services they could remotely, particularly reference.

After a full year of providing fully remote library reference, the authors were interested in exploring the impact COVID-19 related changes had on reference services themselves, as well as the perceptions of those who provide them. As adopting remote reference was more or less mandatory in this environment, what would the response to these changes be? 


\section{Context of the current study}

\section{Institutional background}

The City University of New York (CUNY) is "the nation's largest urban public university" (About CUNY, n.d.) with 25 campuses in all five boroughs of the city. There are 11 senior colleges, seven community colleges, six graduate or professional schools, and one honors college. Twenty three of the 25 campuses have their own library or libraries. Only the Macaulay Honors College and the School of Labor and Urban Studies do not, instead relying on partnerships with other campuses for library services. The campus libraries operate largely independently of each other, but also all participate in a robust system-wide resource sharing program for print materials and share in the purchase of many large electronic resource packages at the CUNY-wide level. Assisting in this is the Office of Library Services (OLS), that manages these shared services and platforms and coordinates university-wide subscriptions, among other duties.

The CUNY Libraries employ people in various roles and levels, and librarians are considered faculty at their respective campuses. Library workers include full-time and part-time (adjunct) librarians, archivists, full-time and part-time support staff, and student workers. While the exact number of people employed in CUNY libraries is always changing and difficult to pinpoint, the CUNY Libraries email listserv (CULIBS) currently has over 530 subscribers.

\section{Brief COVID-19 shutdown timeline}

On the week of March 9th, 2020, the situation in the New York City area was rapidly deteriorating as more and more cases of COVID-19 were confirmed. At the start of the week, it started to feel like a move to remote learning and work would be likely, and by the end of the week it had become a reality. Then, New York State Governor Andrew Cuomo made an announcement on the afternoon of March 11th, 2020 that all CUNY and SUNY (State University of New York) classes would be moving online after a week-long pause. For most CUNY Libraries, March 13th, 2020 would be the last day on campus providing regular in-person services. While several campuses continued to provide varying levels of in-person service for another week or more, by the end of March 2020, all CUNY libraries were operating remotely. These remote operations continued to last through the entire 2020-2021 academic year, though some level of in-person services has resumed for the start of the 2021-2022 academic year. 


\section{Literature review}

Remote, or virtual, reference has been around for many years in various formats. While occasional experiments in the mid-late 2000s were made into using virtual spaces like Second Life to conduct reference interactions, modern remote reference has been dominated by email, webform submissions, social media interactions, and chat. Much of the recent literature focuses on the analysis of chat transcripts to explore user experience (Pomerantz \& Luo, 2006; Ruppel \& Vecchione, 2012), evaluate services (Hunter, Kannegiser, Kiebler, \& Meky, 2019; Luo, 2008) or librarian performance (Hyde \& Raymond, 2006), and to improve library services (Berndt-Morris \& Minnis, 2014; Brown, 2017; Fuller \& Dryden, 2015). Others approach chat reference as a tool, exploring popups (Fan, Fought, \& Gahn, 2017; Imler, Garcia, \& Clements, 2016) and proactive chat (Kemp, Ellis, \& Maloney, 2015; Warner, 2019). Outside of the aforementioned areas, there are several areas of focus in the literature covered in this literature review: reference service overviews, librarian perceptions of remote reference, and remote reference as part of academic libraries' COVID-19 response.

\section{Overviews of virtual reference programs}

Recent articles that provide a broad exploration of chat reference services include Nicol and Crook (2013), who looked at the implementation and success, along with user rates, of virtual reference services at Washington State University, Pullman. Yang and Dalal (2015) conducted a content analysis of academic library websites to see what types of virtual reference they provide. Of the libraries in their sample, nearly half offered chat reference, and of those, under $20 \%$ were part of a chat consortium, while the rest provided in-house coverage for the service (2015, p. 71). Côté, Kochkina, and Mawhinney (2016) stated "The main goal of the study was to obtain a broad and comprehensive picture of the current service, grounded in the actual day-to-day provision, usage, and organization of the service" (2016, p. 37). Alexander and Wakimoto's (2019) case study used the libraries in the California State University system to document the reference services offered-including remote reference-and investigate "the benefits and challenges of chosen models, as well as the decision-making processes used for both selecting and changing those models" (2019, p. 22).

\section{Librarian response to remote reference}

There is relatively little that examines librarian response to providing remote reference. In their 2011 systematic review of the literature on chat 
reference, Matteson, Salamon, and Brewster (2011) found only two articles that addressed librarian responses to remote reference.

Janes and Hill's article Finger on the Pulse: Librarians Describe Evolving Reference Practice in an Increasingly Digital World (2002) is an informal study that asked librarians about many aspects of their response to a then fairly new mode of providing reference. Many of the concerns librarians lay out in this article are ones that will be repeated throughout the literature. The authors note that "one-third of the responding librarians mentioned that answering reference questions digitally was more time consuming" (2002, p. 60). One librarian interviewed mentioned the question of whether to show or tell the patron how to find what they need, saying "I have found myself debating whether to tell someone how to do something online, which would mean a lot of typing, or just pushing the results of what I've done to them. Saves a lot of time, but could they do it next time?" (2002, p. 60). Janes also conducted a more formal study, Digital Reference: Reference Librarians' Experiences and Attitudes (2002), as a follow up to the previous article. Janes' conclusions in both articles are that librarian response to virtual reference, including chat, is mixed. Many interviewed indicated they preferred in-person reference, but understood that adapting to new technologies was important for libraries to reach patrons and maintain relevance. The University of Texas at Arlington's Virtual Reference Service: An Evaluation by the Reference Staff (Casebier, 2006) reports on a survey conducted in 2003-2004 where librarians were asked about their experiences with a newly implemented in-house chat program, and the switch to a cooperative chat program, and concludes that "no matter how many 'bells and whistles' are added, most library workers do not enjoy this reference tool" (2006, p. 136). Gronemyer and Deitering (2009) conducted a study on librarian attitudes toward teaching in the (broadly defined) virtual reference environment, in which they explored librarian response to platforms for virtual reference as well as librarian's feelings about the information seeking behavior of patrons. The most recent study on librarian response to virtual reference is Hendricks and Buchanan's From Exhaustion to Exhilaration: Assessing Librarian Job Satisfaction with Virtual Reference (2013). Like others before, the authors find response to providing reference via chat through a cooperative model decidedly mixed. As with Janes, the authors found many librarians felt tension "between just answering the question or teaching the patron how to answer his or her own question" (2013, p. 58).

\section{Academic libraries COVID-19 response}

In the past year, overviews have been published examining how academic libraries have changed their services in response to the COVID-19 
pandemic. As these are all surveys of the changes in library services, and include remote reference as part of the overall library response to COVID19 campus closures, the discussion is limited. Mehta and Wang (2020), Walsh and Rana (2020), and Connell, Wallis, and Comeaux (2021) all briefly touched on new or expanded chat reference services as part of their COVID-19 response. What is missing from these discussions are the specifics of how libraries changed or added to their services, or what the staff and librarian response was to the shift to fully remote reference services.

\section{Methodology}

This exploratory study used a qualitative research design to collect data on CUNY Libraries' remote reference services offered during the COVID19 campus closures, and of library workers' response to and perceptions of providing reference remotely. An online survey was conducted, using the CUNY libraries email listserv as a distribution platform.

\section{Research questions}

This study sought to explore the following research questions:

- How have the COVID-19 campus shutdowns and the transition to and ongoing remote work affected how CUNY Libraries conduct reference?

- How do CUNY librarians/library staff feel about the work of remote reference?

- How do CUNY librarians/library staff feel about the workload of remote reference?

- What challenges did CUNY librarians/library staff face in shifting to all-remote reference services?

\section{Population and data collection}

The survey was limited to CUNY libraries, and was conducted in February 2021, at a time when all CUNY libraries were closed for in-person reference services, and had been since March 2020. The survey consisted of between 12 and 20 questions (depending on certain responses, see the Appendix), with a mix of closed choice and open-ended questions. It was sent out via the CUNY libraries email listserv, CULIBS. Membership in CULIBS is open to anyone who works in a CUNY library, including full and part time faculty and staff. As of this writing, CULIBS has over 530 subscribers. Not everyone who works in a CUNY library is subscribed to 
CULIBS, and many people ignore or miss emails that come over the listserv. After our initial listserv request, we reached out individual library heads of reference and asked them to circulate the survey within their departments.

\section{Data analysis}

The closed choice questions were analyzed using Excel to visualize the responses in different ways, for example responses of community college librarians and senior college librarians, or those whose libraries participated in a cooperative chat and those that did not. The responses to the openended questions were coded using a structured system (a seven-category rubric) agreed upon by both researchers. The comments were coded separately by each researcher and any discrepancies compared and resolved.

\section{Findings and discussion}

At the end of the survey period, there were 80 responses, representing 19 campuses. Responses came from all seven of the community colleges, all 11 of the senior colleges, and one of the graduate schools (see the Appendix for a list of the campuses represented in the survey results). For questions pertaining to the library as a whole, answers from each library are reported here in aggregate, while those pertaining to individual librarians' perceptions are reported in full.

\section{Reference services}

Prior to the campus closures, just over half of the campuses had an existing chat reference service, see Figure 1. Of those that already had a chat service,

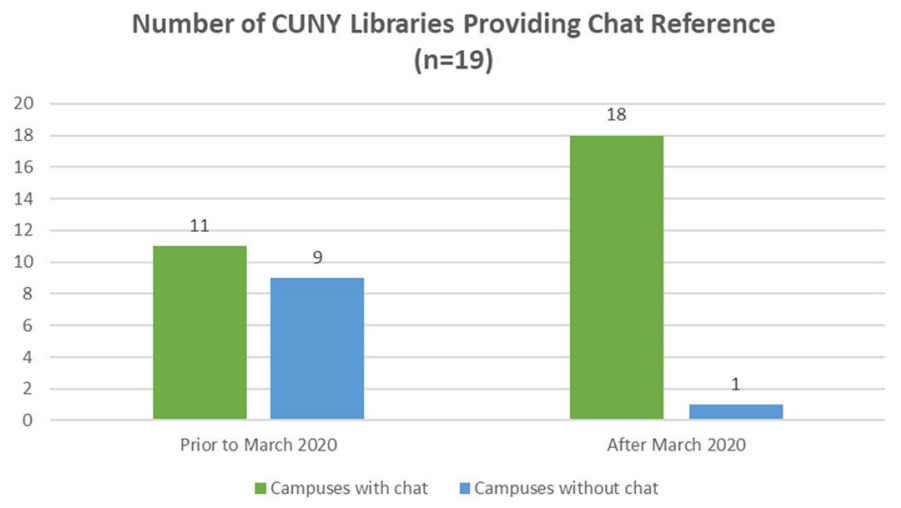

Figure 1. CUNY Libraries' chat services. 
all but one (John Jay) were part of a co-op with other libraries. John Jay was the only campus to also report they were using LibraryH3lp, while all other libraries were using Springshare's LibAnswers platform. Only one campus that responded (Kingsborough) reported that they did not implement a chat reference service when moving to fully remote services indicating that the primary reason they did not was cost. Of the 18 campuses that have chat now, 11 are in a chat consortium and seven are not. All campuses (including Kingsborough) offer non-chat options for reference and research consultations, including email, phone, and video consultations.

While several CUNY libraries had been participating in a reference cooperative using Questionpoint for several years, and were thus used to providing some reference via chat, they were also put in the position of having to shift to providing all of their reference through this method. In addition, due to the purchase of Questionpoint by Springshare in May 2019, libraries that had been using Questionpoint had already been scheduled to shift to using the LibAnswers platform during the spring of 2020, so while they were accustomed to providing reference by chat they still had to learn a new platform.

For most campuses, the addition of a chat service was the most logical step in attempting to provide the same level of reference services in a disrupted pandemic landscape. This allowed libraries to do their best at having synchronous services that could attempt to meet students' needs. Almost every library responding to the survey indicated that they made their chat services more visible or prominent on their library websites, LibGuides, and in some cases even embedded within the library's catalog. Figure 2 details these campus level service changes.

In addition to increased visibility and hours, many libraries made changes to staffing to better meet user needs, with the inclusion of non-reference librarians and library administrators on the reference rotation. Figure 3 shows the staffing changes from pre-COVID to present. Post March 2020, paraprofessional staff were less utilized in the reference rotation, likely in part due to the lack of funding for professional staff positions during this time.

\section{Peer perceptions}

Both authors were curious how librarians throughout the system felt about the shift to offering basically all of CUNY library's reference services remotely. The initial hypothesis was that responses might differ between libraries that were previously doing some reference over chat or between different types of institutions, the breakdown in responses was roughly the same regardless of how the data was parsed. 


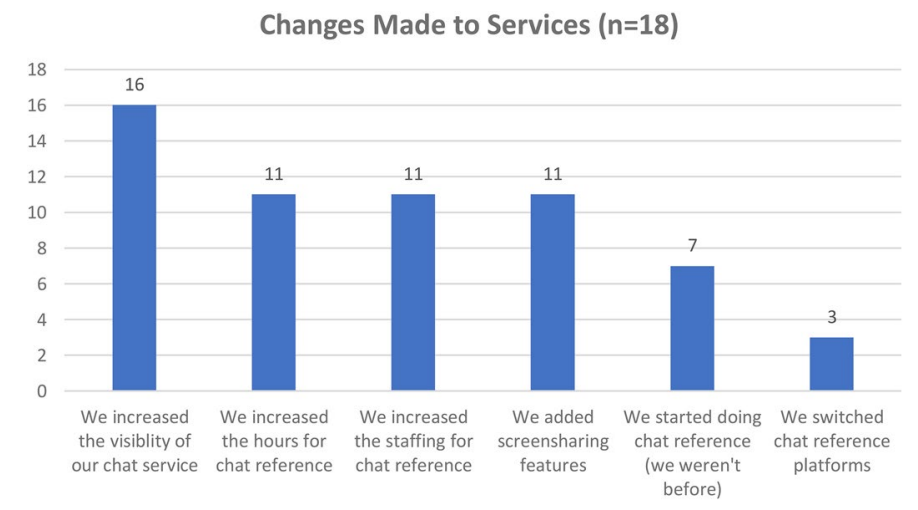

Figure 2. Changes to reference services.

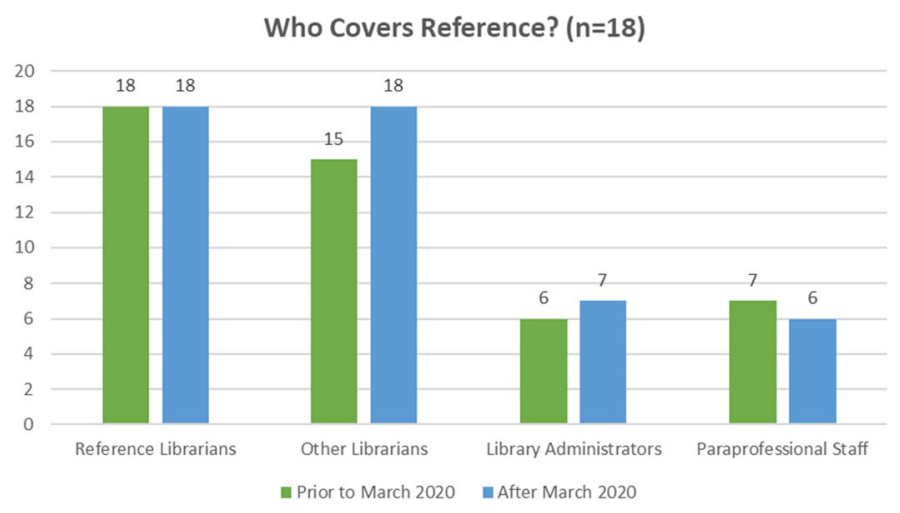

Figure 3. Who is responsible for reference coverage.

When asked how they felt providing reference by chat compared to in-person reference interactions, the overwhelming majority of respondents indicated that it was either on par or harder than in-person work (See Figure 4). As a follow-up we asked for optional elaboration, where we received a range of responses. Several mentioned the challenges in communicating in writing or not as easily being able to see what the patron would see (either because they were unable to or unwilling to do a screenshare session). Similarly, there were several responses that mentioned that they felt more inclined to "tell rather than show." Many librarians' standard model at the in-person reference desk is showing patrons the process so they can later replicate it; the feeling with chat reference was that users wanted an answer quickly and accurately. As one colleague put it "I do a lot more of 'here's a link to the results of a search for your needs' rather than 'here's how to get to what you need and I'll be here waiting if you need more help"' Another commented on the challenges of doing an in-depth reference interview via chat by saying "Communicating with some 
Do You Feel Like Providing Reference by Chat Is... ( $n=75)$

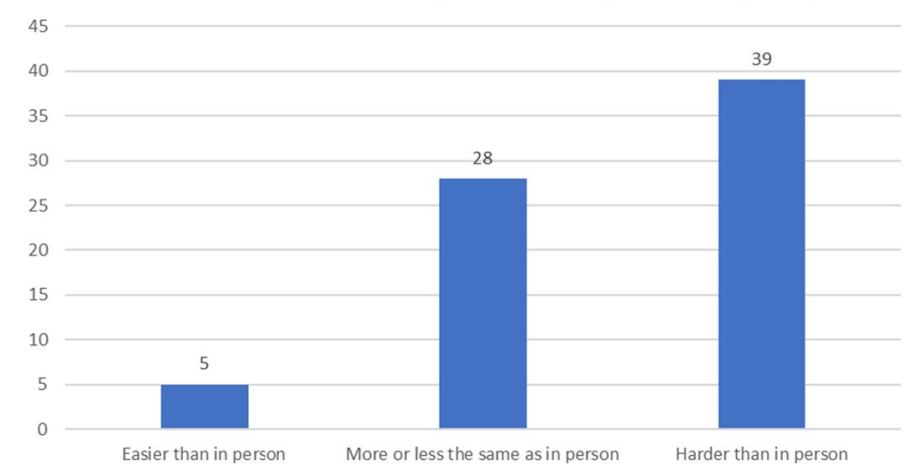

Figure 4. Perceptions of remote reference.

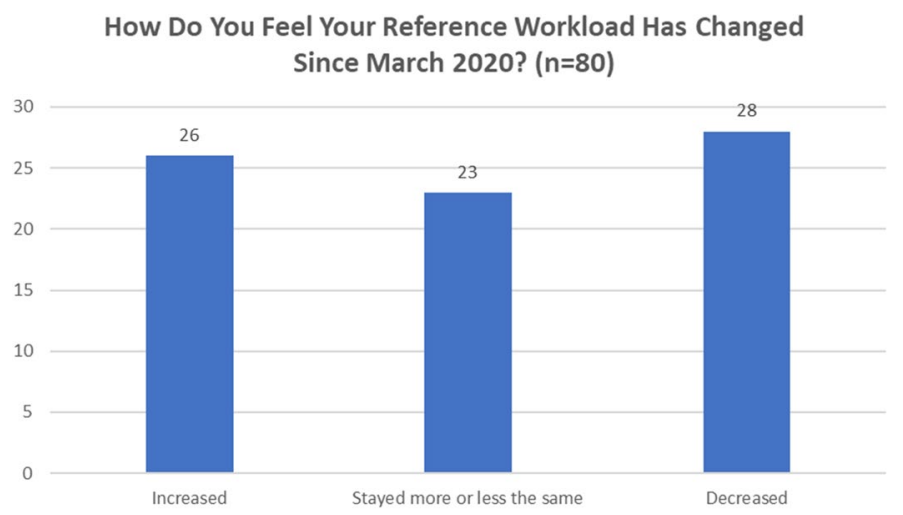

Figure 5. Remote reference workload.

students via chat requires more patience and sometimes more probing for what the student is requesting help with."

The authors were also curious how CUNY librarians felt about their reference workloads with the shift to predominantly chat-based reference services. Perhaps most interesting was that there was no clear consensus, as shown in Figure 5. While some indicated that it felt like they were very busy answering a steady stream of chats or that handling chats felt like more work, many others indicated that they were surprised to see or concerned over a lack of chat volume. This seemed to vary campus-by-campus but not across institution type, institution size, or if the library was previously offering chat. One respondent commented on the "Huge, huge, immense drop in volume-from roughly 40 patrons per two-hour shift during a busy time to 0,1 , or 2 patrons per shift now." It should be noted that New York City was one of the earliest and hardest hit locations in the United States, and in the initial stages of the shutdowns, many CUNY students lacked the necessary technology (both computers and internet 
access) to effectively do online school, including seeking help from a library they might regularly use when on campus.

The abrupt shift to remote learning caused disruptions for all aspects of higher education. These disruptions were noted at the virtual reference desk by multiple respondents. "I am surprised they are using it less than they would in person. When we are open, the place is a beehive of activity. I basically don't feel like we are connecting to students as much as usual. But we are definitely here and trying!"

Several colleagues also expressed concern that students may not be getting the help they needed from the library because they weren't seeing the kind of volume that was typical in-person. One community college colleague said that while being less busy meant they could take their time with individual patrons that did come for help, they "feel terrible about all the students [they weren't] seeing now." And another said "[...] despite emails and urging faculty to urge their students, it's like a ghost town." In regards to chat services in particular, it remains to be seen what the exact impact the pandemic has had on student use of virtual reference, and whether or not libraries that previously did not offer it will continue to do so, and whether or not patrons will continue to use it.

\section{Training}

Although a substantial number of libraries were offering chat reference prior to the shutdown, changing chat platforms or adding new members to the reference rotations (not to mention the libraries that had to start a chat program from scratch!) meant that training was necessary, both in terms of the platform technology, but also in the methods and etiquette of chat reference. Many respondents indicated that they had received chat reference training either at a previous job or in library school. Others indicated that they had platform-only training with one saying, "My training was about an hour long. It was a walkthrough of the layout of how LibChat works. It was very simple and straightforward." And still others received no training at all, but were instead left to "figure it out on [their] own."

Beyond training in the mechanics of using their chat platform, some librarians without experience with internet culture or online communication styles may have needed etiquette training they did not receive. The nuances of communication are different between chat and in-person interactions, and there were mentions of colleagues not realizing that, for example, typing in all caps is considered equal to "yelling" on the internet. As one colleague stated, "My training for chat ref. comes from years ago 
when my library was part of a co-op. However, the majority of my colleagues have zero training and it shows in their transcripts."

\section{Additional challenges}

The transition to all remote reference has not been without challenges. Areas highlighted by survey respondents include scheduling coverage, training, rude patrons, and the effects of working from home full time. As one respondent put it, there is just "So. Much. Typing." A few respondents pointed out that their home internet service was spotty, which would sometimes lead to them dropping chats (something that would never happen in an in-person interaction).

For those librarians responsible for scheduling reference coverage, the change in service meant a change in how coverage is scheduled. One librarian said "The schedule is a challenge, as we have multiple queues and departments. Along with that, anticipating quiet times and peak times because I want everyone to be answering questions." Another indicated that enforcement was a particular problem in that "not enough honor their given/scheduled hours for ref chat, in that they arrive late or leave early."

Many respondents indicated frustration with rude or dismissive behavior from patrons while covering chat reference with one saying, "some [patrons] are on the rude side, impatient, or walk away from the chat w/o letting us know." At least one person attributed this to the anonymity of the chat platform "now that we are not face-to-face, patrons tend to be a bit more demanding, and at times rude." This, coupled with the low usage of remote reference services suggests that chat from the librarian perspective is not as rewarding of an experience than face to face interactions.

Another theme in a few of the responses was that for students, the lines between different campus departments (often unclear at the best of times) have become even more blurred, as all student services moved online. While under normal in-person conditions it would be easy to tell a student to go to a different building, room, or floor for the help they needed, online students seemed to have an expectation that we could answer any question from anywhere. This, of course, can place an unfair burden on library faculty and staff when students come in with unreasonable expectations. One colleague summarized it as "For some reason, we now get all questions-for bookstore, student services, e-tutoring, etc. and these students are more annoyed/confused than before when I draw distinctions between parts of the college and let them know who they actually need to get in touch with." 
Another undercurrent among some respondents was their distrust or dislike of consortial chat models, where librarians from other institutions (and even other countries) are answering their community's questions. One colleague described their concern as "I guess I don't really trust that they'd have a good experience with a random librarian at another kind of institution, [...] but to them it'd still be our library that had failed them if they don't." CUNY does have its own local chat consortium, with several colleges within the University electing to participate. (Many of the participating libraries were ones that had participated in Questionpoint's cooperative chat in the past.) It is possible that new chat consortia may prove to be the bridge between the limitations of locally staffed chat and the problems of a world-wide chat consortium, though the perceptions of that would comprise a totally new study.

\section{Limitations}

As this study is limited to one public university system that went remote in March 2020 and stayed remote throughout the 2020-2021 academic year (even as colleges and universities in other parts of the country had reopened), the results may not be directly applicable to all academic libraries. However, in light of the relatively small body of literature about librarian perceptions and response to online reference, specifically chat, this study provides an update to the articles published in the early 2000s.

Prior to the shift to fully remote reference, CUNY Libraries' reference practices were varied. This has implications on the ability to draw comparisons to volume of reference questions before and after campus closures. We are relying on respondents' perceptions of reference, rather than statistics of reference transactions logged. However, multiple respondents noted the marked difference between the before and after, comparing lines at the reference desk and a reference shift spent busy helping students, to the comparative quiet of remote reference and a shift where only a handful of questions come in.

Further investigation into librarian responses to non-pandemic chat services and identifying areas of interest from this particular survey for further study (most notably, patron abuse of staff on chat or perceptions around chat co-ops), is welcomed and warranted. An examination of librarian responses as a way to inform future updates and improvements to online reference practices and platforms would benefit from the preliminary work presented in this study. While narrow in scope, the findings of this paper nevertheless support future investigations into the area. 


\section{Conclusion}

This survey explored how CUNY Libraries shifted to remote reference services during the COVID-19 campus closures, as well as library workers' response to this shift. Libraries expanded reference hours, added chat services, and increased visibility of reference options. Librarians noted the benefits and drawbacks to providing fully remote reference with some enjoying it and others longing for the relative ease of in-person reference conversations.

By and large, those librarians who responded indicated their commitment to ensuring their students receive the same quality of help as they would in person, regardless of their feelings on providing reference via chat and their own struggles in adapting to the pandemic work environment. And while it remains to be seen whether those libraries that adopted chat because of campus closures will keep it upon returning to campus, there are clear implications for implementing strong and ongoing reference training programs regardless of platform.

Due to the distributed nature of the CUNY systems, many of the areas of concern identified in the survey cannot be addressed by the authors. It is the authors' hope that by drawing attention to the issues, individual libraries, where Chief Librarians and Heads of Reference have the ability to enact change, will take these as a starting point to inform the future of their reference practices, whether in-person or remote.

Overall, whatever their feelings about providing reference remotely prior to the pandemic, CUNY librarians have adapted, despite the challenges. This exploratory study of the reference practices of librarians during the COVID-19 campus closures sheds light on the lengths that academic librarians will go to ensure a continuity of services even during an uncertain time, and serves to illuminate librarian feelings about the work of remote reference.

\section{ORCID}

Sarah Cohn (D) http://orcid.org/0000-0001-8015-4170

Rebecca Hyams (D) http://orcid.org/0000-0001-8177-8946

\section{References}

About CUNY. (n.d.). City University of New York. Retrieved September 22, 2020, from https://www.cuny.edu/about/

Alexander, S., \& Wakimoto, D. K. (2019). Exploration of reference models in a public university system. Reference Services Review, 47(1), 21-36. doi:10.1108/RSR-08-20180062 
Berndt-Morris, E., \& Minnis, S. M. (2014). The chat is coming from inside the house: An analysis of perceived chat behavior and reality. Journal of Library \& Information Services in Distance Learning, 8(3-4), 168-180. doi:10.1080/1533290X.2014.945833

Brown, R. (2017). Lifting the veil: Analyzing collaborative virtual reference transcripts to demonstrate value and make recommendations for practice. Reference \& User Services Quarterly, 57(1), 42-47. doi:10.5860/rusq.57.1.6441

Casebier, K. D. (2006). The University of Texas at Arlington's virtual reference Service: An evaluation by the reference staff. Public Services Quarterly, 2(2-3), 127-136. doi:10.1300/J295v02n02_09

Connell, R. S., Wallis, L., \& Comeaux, D. (2021). The impact of COVID-19 on the use of academic library resources. Information Technology and Libraries, 40(2), 1-20. doi:10.6017/ital.v40i2.12629

Côté, M., Kochkina, S., \& Mawhinney, T. (2016). Do you want to chat? Reevaluating organization of virtual reference service at an academic library. Reference \& User Services Quarterly, 56(1), 36-46. doi:10.5860/rusq.56n1.36

Fan, S. C., Fought, R. L., \& Gahn, P. C. (2017). Adding a feature: Can a pop-up chat box enhance virtual reference services?Medical Reference Services Quarterly, 36(3), 220-228. doi:10.1080/02763869.2017.1332143

Fuller, K., \& Dryden, N. H. (2015). Chat reference analysis to determine accuracy and staffing needs at one academic library. Internet Reference Services Quarterly, 20(3-4), 163-181. doi:10.1080/10875301.2015.1106999

Gronemyer, K., \& Deitering, A. (2009). "I don't think it's harder, just that it's different": Librarians' attitudes about instruction in the virtual reference environment. Reference Services Review, 37(4), 421-434. doi:10.1108/00907320911007029

Hendricks, A., \& Buchanan, S. (2013). From exhaustion to exhilaration: Assessing librarian job satisfaction with virtual reference. Library $\mathrm{Hi}$ Tech, 31(1), 42-63. doi:10.1108/07378831311303921

Hunter, J., Kannegiser, S., Kiebler, J., \& Meky, D. (2019). Chat reference: Evaluating customer service and IL instruction. Reference Services Review, 47(2), 134-150. doi:10.1108/ RSR-02-2019-0006

Hyde, L., \& Raymond, C. T. (2006). Benchmarking librarian performance in chat reference. The Reference Librarian, 46(95-96), 5-19. doi:10.1300/J120v46n95_02

Imler, B. B., Garcia, K. R., \& Clements, N. (2016). Are reference pop-up widgets welcome or annoying? A usability study. Reference Services Review, 44(3), 282-291. doi:10.1108/ RSR-11-2015-0049

Janes, J. (2002). Digital reference: Reference librarians' experiences and attitudes. Journal of the American Society for Information Science and Technology, 53(7), 549-566. doi:10.1002/asi.10065

Janes, J., \& Hill, C. (2002). Finger on the pulse: Librarians describe evolving reference practice in an increasingly digital world. Reference \& User Services Quarterly, 42(1), $54-65$.

Kemp, J. H., Ellis, C. L., \& Maloney, K. (2015). Standing by to help: Transforming online reference with a proactive chat system. The Journal of Academic Librarianship, 41(6), 764-770. doi:10.1016/j.acalib.2015.08.018

Luo, L. (2008). Chat reference evaluation: A framework of perspectives and measures. Reference Services Review, 36(1), 71-85. doi:10.1108/00907320810852041

Matteson, M. L., Salamon, J., \& Brewster, L. (2011). A systematic review of research on live chat service. Reference \& User Services Quarterly, 51(2), 172-190. doi:10.5860/ rusq. $5 \ln 2.172$ 
Mehta, D., \& Wang, X. (2020). COVID-19 and digital library services - a case study of a university library. Digital Library Perspectives, 36(4), 351-363. doi:10.1108/DLP-05-2020-0030

Nicol, E. C., \& Crook, L. (2013). Now it's necessary: Virtual reference services at Washington State University, Pullman. The Journal of Academic Librarianship, 39(2), 161-168. doi:10.1016/j.acalib.2012.09.017

Pomerantz, J., \& Luo, L. (2006). Motivations and uses: Evaluating virtual reference service from the users' perspective. Library \& Information Science Research, 28(3), 350-373. doi:10.1016/j.lisr.2006.06.001

Ruppel, M., \& Vecchione, A. (2012). "It's research made easier!" SMS and chat reference perceptions. Reference Services Review, 40(3), 423-448. https://doi. org/10.1108/00907321211254689

Walsh, B., \& Rana, H. (2020). Continuity of academic library services during the pandemic The University of Toronto Libraries' response. Journal of Scholarly Publishing, 51(4), e51404-245. doi:10.3138/jsp.51.4.04

Yang, S. Q., \& Dalal, H. A. (2015). Delivering virtual reference services on the Web: An investigation into the current practice by academic libraries. The Journal of Academic Librarianship, 41(1), 68-86. doi:10.1016/j.acalib.2014.10.003 


\section{Appendix}

\section{Campuses represented in survey}

Community Colleges

- Borough of Manhattan Community College

- Bronx Community College

- Guttman Community College

- Hostos Community College

- LaGuardia Community College

- Kingsborough Community College

- Queensborough Community College

Senior Colleges

- Baruch College

- Brooklyn College

- College of Staten Island

- Hunter College

- John Jay College of Criminal Justice

- Lehman College

- Medgar Evers College

- New York City College of Technology

- Queens College

- The City College of New York

- York College

Graduate

- CUNY Graduate Center

\section{Survey Questions}

1. Campus (If more than one, answer the questions for your "main" campus)

1. Prior to COVID-related campus closures in March 2020, did your library offer chat reference services?
a. Yes
b. No

2. Does your library currently offer chat reference services?
a. Yes
b. No

3. What platform does your library use for chat reference?
a. LibAnswers/LibChat
b. LibraryH3lp
c. Something else (please describe)

4. Does your library do co-op/shared chat with other libraries?
a. Yes
b. No 
5. What features of chat reference does your library use? (Check any that apply)
a. Chat via Text (SMS)
b. Chat via Social Media (Twitter, Facebook, etc.)
c. Screensharing
d. Other (Please Describe)

6. Did your library make any changes to their chat services in response to COVID-related closures? (Check any that apply)
a. We started doing chat reference (we weren't before)
b. We increased the hours for chat reference
c. We increased the staffing for chat reference
d. We switches chat reference platforms
e. We joined a chat co-op
f. We added screensharing features
g. We increased the visibility of our chat service (made more prominent on our website/ added to LibGuides and/or OneSearch)
h. Other (Please Describe)

7. What other ways, if any, is your library currently providing reference services remotely? (Check any that apply)
a. Email
b. Video conferencing (Zoom, Teams, Collaborate, etc.)
c. Phone
d. FAQs/Knowledgebase
e. Other (Please describe)

8. Who in your library was providing reference services (either in-person or online) prior to March 2020? (Check any that apply)
a. Librarians whose titles include Reference (ex: Reference Librarian, Head of Reference, Reference/Instruction Librarian)
b. Librarians whose titles don't include Reference (ex: E-Resources, Acquisitions, Cataloging, Collection Development...)
c. Library Administration (Chiefs/Deans, etc.)
d. Professional Staff (HEOs, COAs, etc.)
e. Other (Please describe)

9. Who in your library currently (Spring 2021) staffs chat reference? (Check any that apply)
a. Librarians whose titles include Reference (ex: Reference Librarian, Head of Reference, Reference/Instruction Librarian)
b. Librarians whose titles don't include Reference (ex: E-Resources, Acquisitions, Cataloging, Collection Development...)
c. Library Administration (Chiefs/Deans, etc.)
d. Professional Staff (HEOs, COAs, etc.)
e. Other (Please describe)

10. Do you feel like you received sufficient training on your chat platform?
a. Yes
b. No
c. I don't remember

11. Do you feel like you received sufficient training on chat etiquette?
a. Yes
b. No
c. I don't remember 
12. Would you like to tell us more about your experience with receiving training for chat reference?

13. Since March 2020 do you feel that your reference workload has...
a. Increased
b. Decreased
c. Stayed more or less the same
d. I didn't provide reference services before

14. Do you feel that providing reference by chat since March 2020 has been...
a. Easier than in person
b. Harder than in person
c. More or less the same as in person
d. I didn't provide reference services in person

15. Would you like to elaborate on your answers above?

16. What specific challenges, if any, have you faced in providing fully remote reference?

17. Do you have anything you'd like to tell us about reference chat or other online reference services during COVID-related library closures?

- If users selected "No" on question number 3, they were given the following and skipped questions $4-7$ and 9-13

- What were/are the reasons for not implementing chat reference? (Check any that apply)

- Technological Constraints

- Staffing

- Budget Issues

- Other (Please describe)

- If users selected "No" on question 2 but "Yes" to question 3, they were given the following between questions 17 and 18

- If your library didn't have chat reference before March 2020, would you support keeping it after an eventual return to campus?

- Yes

- Yes, depending on staffing

- No

- Other (Please elaborate)

\section{Coding Scheme for open ended questions}
1. Technology
2. Workload
3. Reference Interactions
4. Work from Home
5. Cooperative Chat
6. Other 